\title{
Differences in the system of nitrogen synthesis and content of metabolites in antioxidant systems of sportsmen of different sex
}

\author{
Nadezhda V. Bogdanovskaya, Anastasia V. Golubenko \\ Zaporizhzhya National University, Department of health and physical rehabilitation, Zaporozhye, Ukraine
}

\section{Email address:}

nadezhdabg@rambler.ru (N. V. Bogdanovskaya), ana41171@mail.ru (A. V. Golubenko)

\section{To cite this article:}

Nadezhda V. Bogdanovskaya, Anastasia V. Golubenko. Differences in the System of Nitrogen Synthesis and Content of Metabolites in Antioxidant Systems of Sportsmen of Different Sex. American Journal of Biomedical and Life Sciences. Special Issue: Mechanisms of Protection against Oxidative Stress. Vol. 2, No. 6-1, 2014, pp. 19-24. doi: 10.11648/j.ajbls.s.2014020601.14

\begin{abstract}
The research has been conducted on 26 high qualification sportsmen of different sex, adapted to perform protracted physical activity of high intensity. Determined is the presence of gender differences in oxidizing and no oxidizing metabolism of L-arginine, including also the system of nitrogen oxide synthesis (oxidizing de novo and no oxidizing reutilization ways of NO synthesis), on different stages of their contention activity. On the stage of maximal functional possibilities and adaptation (beginning of contention period) for girls no oxidizing metabolism of arginine predominated with participation of arginase above oxidizing degradation of L-arginine with participation of NO-synthase. During the decline of functional possibilities (desadaptations in the middle and at the end of the competitions) the necessary level of nitrogen oxide synthesis is provided for girls mainly due to nitrogen oxide resynthesis from its stable metabolites, while for youths - due to the increase of oxidizing de novo nitrogen oxide synthesis ( as constitutive, also inducible).
\end{abstract}

Keywords: L-Arginine, NO-Synthase, Ways of Synthesis, Antioxidant System, Physical Loadings, High-Trained Sportsmen, Boys, Girls, Physical Capacity

\section{Introduction}

Gender differences in the reaction of organism to the physical loadings due to the system of synthesis of nitrogen oxide now have not only a theoretical value and are important for general physiology and physiology of muscular activity but also have substantial practical meaning - in connection with possibility of organization scientifically grounded systems of biochemical correction of the functional state of organism in the conditions of long duration action of extreme external factors.

Today most publications are related to the problem of nitrogen oxide, devoted to the question of efficiency estimation of its practical use as the structural element of various bioactive additions, but not to the study of physiology mechanisms of influence of nitrogen oxide on the functional state and functional possibilities of organism during systematic implementation of muscular work and features of re-erecting of the system of NO synthesis at different stages of training and contention activity $[1,9,10$, $15]$.
Unfortunately there are no complex scientific researches, devoted to the indicated question, especially that concern participation of different ways of biosynthesis of nitrogen oxide- oxidizing de novo and no oxidizing reutilizative one in providing the optimum levels of nitrogen oxide at the different functional states, and also gender differences of these processes. Before, we investigated the synthesis of nitrogen oxide for the sportsmen of different sex in a training period of adaptations to the physical loadings [2-4, 8].

Undoubted actuality and practical meaningfulness of the transferred questions became pre-conditions for the leadthrough of this research. The purpose of this work was to study gender differences in metabolism of L-arginine for the high-trained sportsmen of high qualification.

\section{Materials and Methods}

In the experiment 26 sportsmen of high qualification took part in age from 20 to 25 years, who executed muscular work of high capacity and intensities systematically (during 10-12 years). 
In plasma of blood (enriched with white bloody little bodies) of youths and girls who determined biochemical indexes, characteristic is the intensity of arginine exchange after two alternative (no oxidizing arginase and oxidizing NO-synthase) ways of metabolism. Intensity of no oxidizing metabolism was estimated, determining activity of arginase and content of urea which appears during work of this enzyme.

Intensity of oxidizing degradation of arginine (at which nitrogen oxide forms by the way of de novo synthesis) was estimated after activity of different isoferments of NO-synthase - calcium dependant constitutive (total activity of eNOS was determined $+\mathrm{nNOS}=\mathrm{cNOS}$ ) and calcium dependent inducible (iNOS) of nitrogen oxide synthases, and also after the level of circulatory stable metabolitive oxide of nitrogen - nitrite- $\left(\mathrm{NO}_{2}{ }^{-}\right)$and nitrate- $\left(\mathrm{NO}_{3}{ }^{-}\right)$anions.

Estimated was the intensity of no oxidizing reutilization of nitrate anions for resynthases of nitrogen oxide(salvage), determining NADF-dependent nitrate reductive activity. All indicated indexes (in a calculation on $1 \mathrm{mg}$ of general albumen of plasma) determined in plasma of blood in accordance with the previously described methods [1,4].

Using the defined values of indexes, the sizes of correlations of these indexes expected, namely:

- size of index of oxygenation (IO, conditional units) after the next formula of $\mathrm{IO}=\left[\right.$ content of $\left.\mathrm{NO}_{2}^{-}\right] / 1000 /[$ content of $\left.\mathrm{NO}_{3}{ }^{-}\right]+[$content of urea $]$

- part of content of nitrite anion $\left(\% \mathrm{NO}_{2}, \%\right)$ in the total pool of stable metabolite nitrogen oxide after a formula $\% \mathrm{NO}_{2}=$ [content of $\mathrm{NO}_{2}^{-}$] $* 100 /$ [content of $\mathrm{NO}_{3}^{-}$] + [content of $\mathrm{NO}_{2}{ }^{-}$;

- part of activity of iNOS (\%iNOS, \%) in total activity of NO-synthases after a formula: \%iNOS = activity of iNOS / activity[ iNOS + cNOS];

- size of correlation (in conditional units) of activities of no oxidation (arginase) and different ways of oxidizing (NO-synthase) metabolism of arginine through the size of relation of arginase activities and total and different isoferments of NOS (activity of arginase / activity [ iNOS + cNOS], activity of arginase / activity of iNOS and activity of arginase / activity of cNOS;

- size of correlation(in conditional units) of oxidizing de novo and no oxidizing salvage ways of synthesis of nitrogen oxide, determining the size of correlation of enzymes activities of these different ways of synthesis of nitrogen oxide(activity of nitrate reductive / total activity of NOS, activity of nitrate reductive/ activity of iNOS and activity of nitrate reductase / cNOS activity.

The relative changes (D \%) of investigational biochemical indexes expected in relation to a certain period or control after the next formula of $\mathrm{D}=100 *(\mathrm{Xi}-\mathrm{Xn}) / \mathrm{Xn}$.

Biochemical indexes were determined in plasma of blood of the trained youths and girls three times: at the beginning, in the middle and at the end of contention period $(\mathrm{CP})$. Duration of setup time which was preceded $\mathrm{CP}$ made 3 months, in the process of which the physical loadings were executed in default of factors of psychological stress. In a contention period (lasted 8 months) physical loadings were executed both in training in without stress conditions and in stress additional of responsible competitions.

A select chart was based on that we estimated the dynamics of activity change of different ways of nitrogen oxide synthesis at the beginning of contention period (on the peak of physical form of sportsmen, attained in the process of trainings employments), in the middle of contention period (in 8 months after the beginning of trainings and through 3 months after the beginning of competitions) and at the end of contention period (in 11 months after the beginning of trainings and in 8 months after the beginning of competitions).

Simultaneously with biochemical indexes for sportsmen also were determined the size of general physical capacity (Physical Working Capacity $\left(\mathrm{PWC}_{170}\right), \mathrm{kgm} / \mathrm{kmin} / \mathrm{kg}$ ) and size of the aerobic productivity (maximum oxygen transfer rate, $\mathrm{ml} / \mathrm{kmin} / \mathrm{kg}$ (MOTR)) of their organism by the submaximal ergometric test of $\mathrm{PWC}_{170}$.

All the results achieved during the experiment were treated the standard methods of mathematical statistics with the use of statistical package of Microsoft Excel.

\section{Results and Discussions}

By our previous researches was the objective existence of certain dynamics set in the system of synthesis of nitrogen oxide during the protracted training period, that did not depend on sex [1-4]. It is rotined that on the stage of the intensive physical loadings, psycho emotional stress (a period of preparation to the contention season), basic role in providing the organism with nitrogen oxide for the adapted sportsmen (both youths and girls) belongs mainly to the constitutive de novo synthesis and, by less measure, to resynthesis of NO with participation of nitrate reductase at simultaneous ever-higher activity of no oxidizing arginase metabolism of L-arginine.

It was marked that multilevel no oxidizing arginase metabolism of arginine is provided by the organism of sportsmen by low-molecular antioxidants (urea, polyamines) and bioregulators (urea, polyamines, gamma-aminobutyric acid), and also by the predecessors of basic albumen of connecting fabric, - collagen, that have important value for valuable adaptation of organism of sportsmen to implementation of physical work of considerable capacity and duration.

From point of the practical use of results, undoubtedly meaningful for us, there was an exposure of gender features of intercommunication between the different level of functional preparation of high-professional sportsmen $\left(\mathrm{PWC}_{170}\right.$ and MOTR) and level of biosynthesis of nitrogen oxide in various ways (de novo and salvage).

The presented results of inspection of the high-trained sportsmen of different sex at the beginning of contention period which is characterized by the highest level of physical preparedness of organism, testify that in the group of youths registered for certain more high, than in girls, sizes of functional parameters of $\mathrm{PWC}_{170}$ and MOTR (table. 1 and table. 2). 
Table 1. The expected indexes of high-trained youths and girls at the beginning of contention period $\left(x^{-} \pm m\right)$.

\begin{tabular}{llll}
\hline Indexes & Girls & Youth & D, \% \\
\hline $\begin{array}{l}\text { Arginase, nmole/min mg of } \\
\text { albumen } \\
\text { cNOS, pmole/ min mg of }\end{array}$ & $2,69 \pm 0,32$ & $2,09 \pm 0,28$ & $-22,25$ \\
$\begin{array}{l}\text { albumen } \\
\text { iNOS, pmole / min mg of } \\
\text { albumen }\end{array}$ & $48,01 \pm 4,50$ & $58,49 \pm 3,85$ & 21,82 \\
$\begin{array}{l}\text { Nitratereductase, nmole/ } \\
\text { min mg of albumen }\end{array}$ & $4,62 \pm 0,25$ & $3,47 \pm 0,19 * *$ & $-25,02$ \\
$\begin{array}{l}\text { Nitrite-anion, pmole/ mg of } \\
\text { albumen }\end{array}$ & $296,87 \pm 36,22$ & $324,54 \pm 20,56$ & 9,32 \\
$\begin{array}{l}\text { Nitrate-anion, nmole/mg of } \\
\text { albumen }\end{array}$ & $1,36 \pm 0,14$ & $1,67 \pm 0,15$ & 22,63 \\
$\begin{array}{l}\text { Urine, nmole/mg of } \\
\text { albumen }\end{array}$ & $71,98 \pm 7,56$ & $75,83 \pm 2,19$ & 5,35 \\
$\begin{array}{l}\text { General physical capacity, } \\
\text { kgm/min/kg }\end{array}$ & $20,24 \pm 0,58$ & $27,14 \pm 1,49^{* * *}$ & 34,12 \\
$\begin{array}{l}\text { Aerobic productivity, } \\
\text { ml/min/kg }\end{array}$ & $59,99 \pm 1,27$ & $71,14 \pm 3,26 * *$ & 18,59 \\
$\begin{array}{l}\text { Arginase, nmole/min mg of } \\
\text { albumen }\end{array}$ & $2,69 \pm 0,32$ & $2,09 \pm 0,28$ & $-22,25$ \\
\hline
\end{tabular}

Note: here and farther $* * *, * * *$ - a difference is reliable $(\mathrm{R}<0,05,0,01,0,001)$ in relation to a value in the group of girls, D are sizes of relative difference $\%$.

Table 2. Expected indexes of the high-trained youths and girls at the beginning of contention period $\left(x^{-} \pm m\right)$.

\begin{tabular}{llll}
\hline Indexes & Girls & Youth & D, \% \\
\hline Arginase / cNOS, c.u. & $61,09 \pm 8,67$ & $37,68 \pm 6,13^{*}$ & $-38,32$ \\
Arginase / iNOS, c.u. & $381,76 \pm 55,58$ & $172,23 \pm 23,94 * * *$ & $-54,89$ \\
Nitrate reductase/cNOS, & $107,04 \pm 11,90$ & $62,00 \pm 5,19^{* * * *}$ & $-42,08$ \\
c.u. & & & \\
Nitrate reductase/iNOS, & $739,59 \pm 114,13$ & $289,38 \pm 19,92^{* * * *}$ & $-60,87$ \\
c.u.. & $5,86 \pm 1,91$ & $4,24 \pm 0,31$ & $-27,66$ \\
Oxinisation index, c.u.. & $14,83 \pm 1,78$ & $17,75 \pm 1,30^{*}$ & 19,67 \\
Part of iNOS, \% & $67,02 \pm 2,64$ & $65,92 \pm 2,37$ & $-1,63$ \\
\hline Part of NO2, \%
\end{tabular}

It was marked in our previous works, that for all inspected, regardless of sex, a dominant role in providing the optimum level of synthesis of nitrogen oxide on the stage of preparation to the season (on the different stages of training period) belonged to constitutive de novo (cNOS) at participation of salvage way (nitrate reductase) of its formation at simultaneous high activity of no oxidizing degradation of arginine (arginase). At the beginning of contention period activity of nitrate reductase in the group of girls was for certain higher, than for youths. Opposite, among youths the higher values of activities were registered both constitutive (cNOS) and inducible (iNOS) ways of de novo synthesis of $\mathrm{NO}$, that arrived at authenticity of difference for the values of total activity of NOS for youths and girls. For certain youths had higher part of iNOS in total activity of NOS.

For the high-trained girls, optimum adapted to the protracted physical work of large intensity, there were characteristic statistically reliable higher values of correlations of activities both no oxidizing fermentative activities (arginase and nitrate reductase), that does not need oxygen for the work with the sizes of activity of enzymes of oxidizing metabolism (cNOS and iNOS), which require oxygen for the synthesis of nitrogen oxide. Reliable differences in the level of physical capacity and aerobic productivity looked as natural sex differences.

In the middle of contention period (table. 3 and table. 4), which is characterized by powerful external influence on an organism of both trainings and contention loadings, burdened psychological stress, we trace simultaneously the decline of functional preparedness of sportsmen (decline of sizes of general physical capacity maximal consumption of oxygen for youths and girls at the for certain higher values of these indexes in the group of youths) gender differences are certain in relation to the state of the system of synthesis of oxide of nitrogen.

Table 3. Expected indexes of the high-trained youths and girls in the middle of contention period $\left(x^{-} \pm m\right)$.

\begin{tabular}{llll}
\hline Indexes & Girls & Youth & D, \% \\
\hline $\begin{array}{l}\text { Arginase, nmole/min mg of } \\
\text { albumen } \\
\text { cNOS, pmole/ min mg of }\end{array}$ & $1,38 \pm 0,19$ & $1,31 \pm 0,29$ & $-5,03$ \\
$\begin{array}{l}\text { albumen } \\
\text { iNOS, pmole / min mg of } \\
\text { albumen }\end{array}$ & $56,45 \pm 3,05$ & $71,67 \pm 6,42^{*}$ & 26,98 \\
$\begin{array}{l}\text { Nitratereductase, nmole/ min } \\
\text { mg of albumen }\end{array}$ & $3,40 \pm 1,55$ & $10,43 \pm 1,36$ & 32,00 \\
$\begin{array}{l}\text { Nitrite-anion, pmole/ mg of } \\
\text { albumen }\end{array}$ & $348,94 \pm 27,33$ & $378,05 \pm 46,89$ & 8,34 \\
$\begin{array}{l}\text { Nitrate-anion, nmole/mg of } \\
\text { albumen }\end{array}$ & $1,76 \pm 0,07$ & $1,02 \pm 0,13 * * *$ & $-42,18$ \\
$\begin{array}{l}\text { Urine, nmole/mg of albumen } \\
\text { General physical capacity, }\end{array}$ & $77,60 \pm 5,17$ & $57,65 \pm 5,66 * *$ & $-25,71$ \\
$\begin{array}{l}\text { kgm/min/kg } \\
\text { Aerobic productivity, } \\
\text { ml/min/kg }\end{array}$ & $16,61 \pm 0,99$ & $23,86 \pm 0,62 * * *$ & 43,65 \\
$\begin{array}{l}\text { Arginase, nmole/min mg of } \\
\text { llbumen }\end{array}$ & $52,04 \pm 2,24$ & $63,77 \pm 1,30^{* * *}$ & 22,53 \\
\hline
\end{tabular}

Table 4. Expected indexes of the high-trained youths and girls in the middle of contention period $\left(x^{-} \pm m\right)$.

\begin{tabular}{llll}
\hline Indexes & Girls & Youth & D, \% \\
\hline Arginase / cNOS, c.u. & $1,38 \pm 0,19$ & $1,31 \pm 0,29$ & $-5,03$ \\
Arginase / iNOS, c.u. & $56,45 \pm 3,05$ & $71,67 \pm 6,42 *$ & 26,98 \\
Nitrate reductase/cNOS, c.u. & $7,90 \pm 1,55$ & $10,43 \pm 1,36$ & 32,00 \\
Nitrate reductase/iNOS, c.u.. & $3,47 \pm 0,18$ & $2,37 \pm 0,28 * *$ & $-31,86$ \\
Oxinization index, c.u.. & $348,94 \pm 27,33$ & $378,05 \pm 46,89$ & 8,34 \\
Part of iNOS, \% & $1,76 \pm 0,07$ & $1,02 \pm 0,13 * * *$ & $-42,18$ \\
Part of NO2, \% & $77,60 \pm 5,17$ & $57,65 \pm 5,66 * *$ & $-25,71$ \\
\hline
\end{tabular}

In the middle $\mathrm{CP}$, regardless of sex, dominant role in the synthesis of nitrogen oxide belongs to the no oxidizing way of resynthesis of NO from its stable metabolite way, at the maintenance of important role of oxidizing constitutive de novo synthesis. At the same time, in the middle $\mathrm{CP}$ for sportsmen was characteristic for certain higher, than for sportswomen with the lower values of physiology parameters of adaptation and training, activity of constitutive NO-synthase (on 26,98\%), and, opposite, for certain less values of activity of nitrate reductase (on 31,78\%) and concentrations of nitrate anion (on 42,18\%) and urea (on $25,71 \%$ ) in plasma of blood. 
Taking into account, that nitrate is the marker of formation of peroxynitrite at co-operation of superoxide and nitrogen oxide and high levels of synthesis last, it is possible to assume that more powerful antioxidant system, than for sportswomen, functions for sportsmen, or less superoxide is generated. At the same time, for sportswomen registered for certain higher, than for the sportsmen of value of correlations of enzymes activities of no oxidizing and oxidizing ways of synthesis of nitrogen oxide - nitratereductase/cNOS (on 44,46\%) and nitratereductase/iNOS (on 43,28\%).

In the middle of contention period on a background the united action of high physical and psychological loadings and diminishing of role of multistage no oxidizing metabolism of arginine, which provided the high level of adaptation to physical work of both girls and youths, by the synthesis of row of important biological matters, for sportswomen also there was characteristic higher intensity of no oxidizing resynthesis of NO from its stable metabolite, while for sportsmen oxidizing degradation of L-arginine with participation of cNOS took place.

As it was marked in previous publications, at the end of contention period which is characterized by intensive growth of signs of natural fatigue and proper substantial decline of physical capacity of organism and level of adaptation, dominant role in the synthesis of nitrogen oxide belongs to already the constitutive oxidizing synthesis of nitrogen oxide at the maintenance of certain role its no oxidizing resynthesis .

In accordance with these tables 5 and 6 , on this stage of disadaptation for sportsmen (both youths and girls) little place simultaneously with the decline of their physical capacity and aerobic productivity yet and noticeable changes in the synthesis of oxide of nitrogen. So for girls with the low levels of physiology indexes more than among youths were registered, pools a nitrate anion, and, consequently and pools of his predecessor of peroxinitrite (on 62,99\%) and activity of nitrate reductase( on $37,92 \%$ ) in plasma of blood.

Table 5. Expected indexes of the high-trained youths and girls in the middle of contention period $\left(x^{-} \pm m\right)$.

\begin{tabular}{llll}
\hline Indexes & Girls & Youth & D, \% \\
\hline $\begin{array}{l}\text { Arginase, nmole/min mg of } \\
\text { albumen }\end{array}$ & $1,32 \pm 0,08$ & $1,91 \pm 0,07 * * *$ & 44,33 \\
$\begin{array}{l}\text { cNOS, pmole/ min mg of } \\
\text { albumen }\end{array}$ & $31,82 \pm 1,91$ & $38,59 \pm 3,13$ & 21,27 \\
$\begin{array}{l}\text { iNOS, pmole / min mg of } \\
\text { albumen }\end{array}$ & $15,96 \pm 1,50$ & $20,36 \pm 1,42^{*}$ & 27,57 \\
$\begin{array}{l}\text { Nitratereductase, nmole/ min } \\
\text { mg of albumen }\end{array}$ & $3,90 \pm 0,36$ & $2,42 \pm 0,27 * *$ & $-37,92$ \\
$\begin{array}{l}\text { Nitrite-anion, pmole/ mg of } \\
\text { albumen }\end{array}$ & $340,74 \pm 20,56$ & $309,34 \pm 13,70$ & $-9,22$ \\
$\begin{array}{l}\text { Nitrate-anion, nmole/mg of } \\
\text { albumen }\end{array}$ & $3,61 \pm 0,68$ & $1,34 \pm 0,06 * *$ & $-62,99$ \\
$\begin{array}{l}\text { Urine, nmole/mg of albumen } \\
\text { General physical capacity, } \\
\text { kgm/min/kg }\end{array}$ & $70,37 \pm 2,99$ & $65,72 \pm 2,94$ & $-6,61$ \\
$\begin{array}{l}\text { Aerobic productivity, } \\
\text { ml/min/kg }\end{array}$ & $12,47 \pm 0,59$ & $20,81 \pm 1,07 * * *$ & 66,92 \\
$\begin{array}{l}\text { Arginase, nmole/min mg of } \\
\text { albumen }\end{array}$ & $1,32 \pm 0,08$ & $1,91 \pm 0,07 * * *$ & 44,33 \\
\hline
\end{tabular}

Table 6. Expected indexes of the high-trained youths and girls at the end of contention period $\left(x^{-} \pm m\right)$.

\begin{tabular}{llll}
\hline Indexes & Girls & Youth & D, \% \\
\hline Arginase / cNOS, c.u. & $28,41 \pm 2,03$ & $33,24 \pm 1,82$ & 17,01 \\
Arginase / iNOS, c.u. & $43,87 \pm 4,51$ & $51,58 \pm 3,21$ & 17,59 \\
Nitrate reductase/cNOS, c.u. & $83,64 \pm 8,09$ & $42,17 \pm 4,86 * * *$ & $-49,58$ \\
Nitrate reductase/iNOS, c.u.. & $127,28 \pm 12,90$ & $65,68 \pm 8,11^{* * *}$ & $-48,40$ \\
Oxinization index, c.u.. & $4,72 \pm 0,39$ & $4,77 \pm 0,40$ & 1,13 \\
Part of iNOS, \% & $33,33 \pm 3,06$ & $34,82 \pm 2,08$ & 4,48 \\
Part of NO2, \% & $53,20 \pm 4,82$ & $69,69 \pm 1,14 * *$ & 30,99 \\
\hline
\end{tabular}

Opposite, at the end of contention period youths with higher physiology indexes took advantage in activity of both inductible synthesis of nitrogen oxide (on 27,57\%) and constitutive synthesis (on 21,27\%). For sportswomen in this period there was characteristic higher intensity of no oxidizing resynthesis of nitrogen oxide as compared to its oxidizing synthesis with participation of different isoform of NO-synthase.

Thus, the results of the conducted research allowed to establish the presence of certain gender differences in the system of synthesis of nitrogen oxide depending on the stage of adaptation of organism of the trained persons to the physical and psychological loadings.

It was set that in the process of growth of action of these extreme external influences for the trained girls,it is marked the higher intensity of regenerating resynthesis of nitrogen oxide from its stable metabolite, while among the trained youths is the higher level of activity of oxidizing de novo synthesis of NO, different NO-synthases isoformes (both constitutive and inductible).

On the different stages (beginning, middle, end of contention period), the necessary level of synthesis of nitrogen oxide is provided also due to the gradual increase of activity of inductible synthesis of NO, that it was rotined by us as for youths so for girls. Actually, due to a considerable increase last (that, possibly, is primary cause of all changes) it is possible to explain both the gradual decline of activity of constitutive synthesis (it is the before known [6] phenomenon of recirculatory interregulation of iNOS and cNOS activity) and to activity of reductive synthesis of NO (the regulator of which is above all things availability of oxygen [10], but not to substrate, nitrate, the circulatory pools of which, opposite, grow in the dynamics of contention period, as well as pools of nitrite, as a result of, including, limitation of speed of their NO synthesis reutilization.

Growing simultaneously, pools of nitrate (due to diminishing of non-nitrate reutilization) and pools of nitrite specify also and on the possible decline of nitrite reductive activity in plasma of blood, which we did not measure directly. Unexpectedly, it is possible to explain the increase of activity of iNOS also and decline of activity of arginase metabolism of arginine, namely for limitation of ureapoiesis, which, due to formation of ureidosuckcynate [7] can inhibit such necessary for work iNOS resynthesis of arginine from a citrulline in the 
citrulline loop [13].

By reliable reason of growth of iNOS activity(almost exceptionally due to induction of this enzyme) in the process of contention period for sportsmen and for sportswomen, there can be a simultaneous increase of both pools of inductors (inflammatory cytokinites of TNF, Inf-gamma, Il-1 but other) and generation of activator of induction, - super anion oxide [13]. Activating of this enzyme can have negative consequences for work of heart of sportsmen, promoting the apoptosis of cardiomiocytes [11, 14].

To our opinion, materials of the conducted research are the substantial adding to present information in relation to the gender differences of metabolism of L-arginine and role of nitrogen oxide in providing of adaptation to systematic muscular activity.

The prospects of subsequent researches is a leadthrough of more detailed study of degree of functional dependence between the level of physical capacity, from one side, and by the state of the systems of circulation of blood to the synthesis of nitrogen oxide, from other, in the process of the physical trainings.

\section{Conclusions}

Among the sportsmen of different sex with the maximal sizes of physical capacity and aerobic productivity (at the beginning of contention period) a dominant role in providing of optimum level of synthesis of nitrogen oxide belongs to oxidizing constitutive de novo synthesis and to the nonoxidizing reutilizing synthesis at simultaneous high activity of nonoxidizing degradation of arginine by an arginase.

For girls with the maximal sizes of physical capacity and aerobic productivity (at the beginning of contention period), but with the less values of functional parameters than for youths, higher, than youths had activity of nitrate reductase and value of correlations of activities both nonoxidizing fermentative activities (arginase and nitrate reductase), that does not need oxygen for the work, with the sizes of activity of enzymes of oxidizing metabolism (cNOS and iNOS), which require oxygen for the synthesis of nitrogen oxide.

For sportsmen with the maximal sizes of physical capacity and aerobic productivity (at the beginning of contention period) the higher values of activities were registered both constitutive and inducible oxidizing de novo synthesis of NO. For certain, youths had higher part of iNOS in total activity of NOS.

In the middle of contention period, which is characterized by powerful external influence on an organism such as the united trainings and contention loadings, burdened psychological stress, simultaneously with the decline of general physical capacity maximal consumption of oxygen (for youths in a less measure than for girls), regardless of sex, a dominant role in the synthesis of nitrogen oxide belongs to the nonoxidizing way of resynthesis of NO from its stable metabolitive at the maintenance of important role of oxidizing constitutive de novo synthesis.

In the middle of contention period for sportsmen with higher physiology indexes there was characteristic the higher, than for sportswomen activity of constitutive NO-synthase, and, opposite, less values of activity of nitrate reductase and concentrations of nitrate anion and urea in plasma of blood. For sportswomen the higher values of correlations of enzymes activities of nonoxidizing and oxidizing ways of synthesis of nitrogen oxide were registered for certain - nitrate reductase/cNOS and nitrate reductase/iNOS.

At the minimum values of physiology indexes (at the end of contention period) for sportsmen, regardless of sex, a dominant role in the synthesis of nitrogen oxide belongs to oxidizing constitutive de novo synthesis at the maintenance of certain role of its nonoxidizing resynthesis .

Sportswomen with low values of physiology indexes had characteristic higher intensity of nonoxidizing resynthesis of nitrogen oxide as compared to its oxidizing de novo synthesis with participation of different isoforms of NO-synthases (more than was registered for sportsmen pools of nitrate anion and higher activity of nitrate reductase in plasma of blood).

At the end of contention period sportsmen with the higher values of physiology indexes than for sportswomen took advantage in activity of oxidizing de novo synthesis of nitrogen oxide(both inductible and constitutive).

\section{References}

[1] Bazilyuk O.V. The age features of changes of nitrogen oxide system in aorta and plasma at the terms of adaptation to the physical loadings / O.V. Bazilyuk, A.V Kotsyuruba., L.G. Stepanenko // Phys. jour. - 2010. - V. 56 , № 1. - P. 3-12.

[2] Bogdanovskaya N.V. Estimation of role of vascular endothelia in providing the physical preparedness of girls-volleyball players on the stage of intensive competition activity/ N.V. Bogdanovskaya, N.V. Malikov, A.N. Svyatodukh // Announcer of the Zaporozh'je national university. Biological sciences. 2008. - № 1. - P. 40-43.

[3] Bogdanovs'ka N.V. Features of the functional state of vascular endothelia under systematic physical loadings / N.V. Bogdanovs'ka, M.V. Malikov// Phys.jour. - 2008. - V. 54, № 4. - P. 44-46.

[4] Bogdanovs'ka N.V. Synthesis of nitrogen oxide in the period of long-term adaptation to intensive muscular work for sportswomen / N.V. Bogdanovs'ka, G.M. Svyatodukh, A.V. Kotsyuruba, M.V. Malikov // Phys.jour. - 2009. - V. 55, № 3. P. 94-99.

[5] Reutov V.P. NO synthase and nitrite reductase components of nitrogen oxide cycle / V.P. Reutov, E.G. Sorokina // Biochemistry - 1998. - V. 63,ed. 7. - P. 1029-1040.

[6] Akita Y. Exercice-induced activation of cardiac sympathetic nerve triggers cardioprotection via redox-sensitive activation of eNOS and upregulation of iNOS / Y. Akita, H. Otani, S. Matsuhisa // Am. J. Physiol. - 2007. - 292, №5. H2051-H2059.

[7] Bianchi P.G. Use of 5(4)amino 4(5)imidazolcarboxamide ureidosuccinate in inflammatory and degenerative liver / P.G. Bianchi, E. Saccabusi // Minerva Gastroenterol. - 1972. - 18, № 4. - P. 245-256. 
[8] Bogdanovskaya N.V. Role of the system of synthesis of nitrogen oxide in providing of long duration adaptation of organism to muscular work / N.V. Bogdanovskaya, N.V. Malikov // J. Physiol. Sci. - Кіото, 2009. - P. 442.

[9] Defron D.T. Role of nitric oxide in wound healing / D.T. Defron, D. Most, A. Barbul // Curr Opin Clin Nutr Metab Care. - 2000. - 3, № 3. - P. 197-204.

[10] Diwan A.D. Nitric oxide modulates fracture healing / A.D. Diwan, M.X. Wang, D. Jang // J. Bone Miner Res. -2000. - 15, № 2. - P. 342-351.

[11] Kanno S. Attenuation of myocardial ischemia/reperfusion injury by superinduction of inducible nitric oxide synthase / S. Kanno, P.C. Lee, Y. Zhang // Circulation. - 2000. - 101, № 23. - P. 2742-2748.

[12] Sureda A. Relation between oxidative stress and antioxidant endogenous defences during exhaustive exercise / A. Sureda, P. Tauler, A. Aguilo // Free Radic Res. - 2005. - 39, № 12. - P. 1317-1324.
[13] Swamy M. Decreased glutamine synthase, increased citrulline-nitric oxide cycle activities and oxidative stress in different regions of brain in epilepsy rat model / M.Swamy, W.R. Yusot, K.N. Sirajudeen //J Physiol Biochem. - 2011. - 67, № 1. - P.105-113.

[14] Wildhirt S.M. Inducible nitric oxide synthase activation after ischemia/reperfusion contributes to myocardal dysfunction and extent of infarct size in rabbits: evidence for a late phase of nitric oxide-mediated reperfusion injury / S.M. Wildhirt, S. Weismueller, C. Schulze // Cardiocasc. Res. - 1999. - 43, № 3. - P. 698-711.

[15] Ziche M. Nitric oxide synthase lies downstream from vascular endothelial growth factor-induced but not basic fibroblast growth factor-induced angiogenesis / M. Ziche, L. Morbidelli, D.R. Choudhuri // J. Clin. Invest. - 1997. - 99, № 11. - P. 2625-2634. 